Open Access

\title{
Are mothers of sons more traditional? The influence of having son(s) and daughter(s) on parents' gender ideology
}

\author{
Xiaodong Sun ${ }^{1}$ and Kaisheng Lai ${ }^{2^{*}}$
}

* Correspondence:
kaishenglai@126.com
School of Communication and
Design, Sun Yat-sen University, No.
132, Waihuan East Road, Panyu
District, Guangzhou, China
Full list of author information is
available at the end of the article

available at the end of the article

\begin{abstract}
Gender and gender ideology have gained increasing attention from researchers in contemporary social sciences. In recent years, some research evidence also indicates that children can affect parents' social value and social attitudes. Based on the sample from CGSS2013 data $(N=8339)$, this study aims to explore whether children's gender can influence the gender ideology of their parents. Results show that the number of children can significantly influence the gender ideology of their parents, especially for mothers. The influence of having son(s) on parents' gender ideology is significantly moderated by the gender of parents. For mothers, having son(s) can significantly enhance their identity for traditional disposition of gender ideology. The findings help understand the relationship between children's gender and their parents' gender ideology in China.
\end{abstract}

Keywords: Children's gender, Confucian culture, Gender division of labor, Gender ideology, Son preference

\section{Introduction}

Gender is both a biological property to human kind and a social attribute that is constantly under construction and change. We usually refer to the former property as sex and the latter as gender (Udry 2000). World history and gender history are intertwined (Hanks 2007). Gender history is the history of gendered images and gender-based division of labor (Bem 1993). With the improvement of the human social system, gender is gradually being embedded in our social and cultural system of values as the resources and norms to guide people's thinking and behaviors. Interactionism and ethnomethodology have put much effort into revealing the gender display and doing gender that people engage in on a daily basis without any realization. Goffman considered gender display as a process in which the two parties interacting with each other in certain social situations that are seemingly simple, with customary expressions while transmitting personal gender identity (Goffman 1997). Scholars of ethnomethodology believe that gender is an achievement made possible by repeatedly engaging in effortful interactions on a daily basis with strategy. They then coined "doing gender" to present the concept of the ongoing efforts to construct and maintain gender process among individuals. They were trying to bring gender back into the center of the research of interactions in daily lives (West and Zimmerman 1987). The aforementioned efforts of

(c) The Author(s). 2016 Open Access This article is distributed under the terms of the Creative Commons Attribution 4.0 International License (http://creativecommons.org/licenses/by/4.0/), which permits unrestricted use, distribution, and reproduction in any medium, provided you give appropriate credit to the original author(s) and the source, provide a link to the Creative Commons license, and indicate if changes were made. 
gender display or doing gender on a daily basis without realizing them consciously indicate that gender in daily life is not a view or theory that has been clearly revealed to people throughout history but deeply embedded in the structure and operations of the unconscious philosophy, that is, an ideology.

Feminist researchers were the one who put the idea of unconscious gender issues under the spotlight of the core social science research. They critically analyzed gender as a moral order, rather than biological attribute, developed it into a basic analysis concept similar to class and ethnicity, and widely used gender in theoretical and empirical research (Worthman 1995). In-depth analysis of gender issues treats gender as a social structure that parallels economic and political structures-gender structure. This enabled analysis of gender's embeddedness at the individual, interpersonal, and systematic level and its differentiation process as well as its impact on people's attitudes and behaviors (Risman 2004). It follows that, within the structure of family, gender structure can also affect gender ideology and behaviors of family members. The gender of children as part of the family gender structure has also been shown to affect different aspects of family processes (e.g., parental investment, ideology and behavior of reproduction, marital status, mental health, etc.) (Raley and Bianchi 2006). In sum, we believe that the gender of children can affect the parental perception and identity about gender roles and division. In other words, we can make such a theoretical proposition: children can affect the gender ideology of their parents.

Although there exist logical associations in theory, empirical research along this line of proposition in the field of gender ideology are rarely addressed. Researchers are more likely to analyze antecedent gender ideology using socio-economic (Kodagoda 2014), institutional (Cha and Thebaud 2009), and cultural (Roder and Muhlau 2014) factors. In demography, the study of the relationship between parents and children focused on the impact of parents on shaping and reproducing children's gender ideology during the socialization process (Davis and Greenstein 2009). Did empirical studies pay attention to the contrast logical route that having sons and daughters would also affect the parents' gender ideology? Unfortunately, in relevant papers, variables associated with children's impact on their parents (for example, whether the parents have sons or daughters) were more likely to be treated as control variables and elicited very few specific discussions. So far, very few papers discuss specifically the impact of the gender of children on parents' gender ideology (i.e., attitudes on the division of labor in the family, instead of political attitudes, justice attitudes, etc.). Some studies raised the path of analysis "from children to parents," and collected data to verify these analyses (Downey et al. 1994; Warner 1991), but due to their unclear theoretical mechanisms and inadequate representativeness of sample, the findings were severely constrained at the national or regional level without many cultural implications and failed to initiate more in-depth discussions.

Our study attempted to test this possible theoretical proposition that the gender of children is a core factor influencing the gender ideology of parents. It should be noted that the "traditional" and "modern" we are talking about are two categories in the typology in the field of gender ideology. We take neutral analysis perspective and do not make subjective value judgments. We view the tendency of "traditionalism" and "egalitarianism" in gender ideology as a historical consequence due to natural selection and social construction in the process of human evolution and social development. 
Sociological studies should focus on the social and cultural attributes of gender ideology. With 2000 years of Confucian tradition, China has a deep-rooted patriarchal system. The characteristics of traditional patriarchal family structure include also patrilineality and patrilocality (Thornton and Lin 1994). Sons are deemed to be the foundation of family reproduction and thriving, so son preference is deeply rooted in Chinese people's cultural values (Arnold and Liu 1986). Despite modernization and urbanization gradually changing the value orientation of Chinese society, as Ogburn pointed out in his cultural lag theory (Ogbum 1922), son preference still exists in contemporary Chinese society (Yang 2012). Son preference may lead parents of sons, especially mothers, to more conservative social attitudes (Mammen 2011; Oswald and Powdthavee 2010). Studies had shown that the impact of children is greater for the mother than the father. Children make mothers more likely to attend to family life (Bianchi and Milkie 2010). Our research found that, with son preference and patriarchy, having children, especially sons, enhances traditional gender ideological tendencies for mothers.

\section{Literature review and hypotheses}

\section{Gender ideology and its influencing factors}

Gender ideology is "the degree of support for paid work and housework division of labor based on personal ideas of gender division of labor." The core is the attitude and identification with the traditional labor division of the "breadwinner/homemaker" model (Davis and Greenstein 2009; Greenstein 1996). With the advancement of research, the understanding of gender ideology, although still regards gendered division of labor as its essential component, is no longer confined within the family. Davis and Greenstein's research revealed the comprehensiveness of measurements on gender ideology from a number of large social survey projects (Davis and Greenstein 2009), thereby imparting gender ideology with more meanings, such as competitiveness (the work ability of men and women, the return gained from education, political leadership, etc.), emotional intimacy (such as marital conflict), and autonomy (such as female career and independence). These definitions were operationalized in international surveys on topics related to gender ideology and enabled its use in empirical research (Brewster and Padavic 2000; Shu and Zhu 2012).

With the increasing labor market participation of women worldwide, traditional gender division of labor has been challenged (Brewster and Padavic 2000). It additionally led the social sciences to explore its antecedents, mainly from the four dimensions of economics, institutions, culture, and demography. Studies in the economic dimension found that the increase in labor market participation for women (Kodagoda 2014) and the elevation of education level (Shu and Zhu 2012) as well as an increase in income (Gupta 2007) all affect the ideology and behaviors of gender division of labor for individuals and families. Research from the institutional dimension found that the fewer barriers women have to access social economic and professional status, the more likely individuals tend to guard the traditional gender roles in the private sector ( $\mathrm{Yu}$ and Lee 2013). Comparing with flexible labor market, the breadwinner role of males in a rigid labor market affects the gender ideology of males more intensely (Cha and Thebaud 2009). Research in the cultural dimension is more concerned about the impact of cultural traditions and religious beliefs. Traditional cultural values affect gender ideology of immigrants (Roder and Muhlau 2014). Conversion to religions and maintaining a 
certain level of religious activities as well as the recognition of God as a male all increase support for gender traditionalism (Whitehead 2012). Demographic studies focused on gender itself and the impact of gender socialization. Research found that men were more conservative in their gender ideology and much slower than women in transitioning to it (Mason and Lu 1988). Although men's gender ideology has been greatly improved in supporting women's participation in public life and work, they are still rather conservative in family life and child rearing (Taylor et al. 1999). Studies of gender socialization focused on the role of parents in shaping the gender ideology of their children. Children under the perspective of socialization are regarded as a household characteristic and thus became part of the control variables. Some studies have found that the impact of having children had statistical significance (Goldscheider et al. 2014), but most studies suggest that children have no effect on parents' gender ideology (Cha and Thebaud 2009; Shu and Zhu 2012; Whitehead 2012).

\section{Effects of children on the gender ideology of parents}

Current theories generally believe that women are more susceptible to the status of having children and thus will tend to focus on family life when becoming parents. Sociological biology theories believe that an individual is a carrier and organization of genes, and the selfish nature of genes makes them seek continuous replication and reproduction (Dawkins 2016). Such reproduction usually takes two paths: one is achieving direct copies through reproduction and the other one is indirectly by helping relatives, people with similar genes, to achieve the transfer and reproduction of genes (Hamilton 1964). Thus, people are more selfless towards relatives from the perspective of the human genetics. "Paternity uncertainty hypothesis" believes that the mother is $100 \%$ certain that her offspring share their same genes, but the father scores obviously lower than the mother in the certainty of this issue (Buss 1999). This assumption is used to explain many differences in altruistic tendencies from biological parents. In a society with uncertain paternity, maternal relatives are more selfless with the offspring than the paternal relatives (Alexander 1974). This is supported by empirical research comparing parents' behaviors (Alvergne et al. 2009). Based on the above evidence, we can expect mothers are more devoted to child rearing and housework than fathers.

A similar argument can be deducted from gender division of labor in economic theories. Family economics see marital relationships as rational cooperation between both spouses. In order to maximize economic utility, couples tend to take a strategic course of action. Activities as a family are divided into domestic labor and the labor market outside of the household (Becker 1991). In a society where income is generally higher for male than female, men become more involved in the labor market and reduce involvement with domestic labor; women become more involved with domestic labor and reduce presence in the labor market. This has become a rational tactic for family activities.

Due to the rare empirical studies that focused on children's influence on parental gender ideology, the authors had to refer to the impact of children on gendered division of labor of parents to infer a potential model looking at the gender ideology of parents. A lot of empirical research supported the biological and economic arguments above. Women with children increased their domestic labor participation and reduced their labor market participation. Studies found that having children and the increase of the 
number of children will both reduce the working hours of women (Kaufman and Uhlenberg 2000). Greenstein's study found that (as a control variable) the higher the number of children, the less the proportion of domestic labor undertaken by the husband with a corresponding increase in domestic labor participation for the wife (Greenstein 1996). Evertsson's research showed that, compared to childless families, father and mother in families with two or more children spend significantly more time on domestic labor work, but the increase for the mother (3.992 h/week) is much higher than for the father (1.459 h/week). Thus, the proportion of men's participation in domestic housework reduces (Evertsson 2014). Additionally, the expectation of having children will also lower the career expectation for women (but not men) (Bass 2015).

Theoretical and empirical research shows that the effect of children on parents is greater for the mother than the father. It also leads women's actions to a more traditional tendency. We expect to see a similar impact of children on gender ideology of parents. Since our sample is focused on married couples with children, this study will examine the effect of the number of children on the gender ideology of parents, and the hypothesis is as follows:

Hypothesis 1: With an increase in the number of children, the gender ideology of parents (especially mothers) exhibits a more traditional tendency.

\section{Sons, daughters, and the process of families}

If children's influence on the gender ideology of parents is established, then do the impact of sons and daughters to fathers' and mothers' gender ideology have significant differences? Existing studies suggest that sons and daughters would have different effects on the process of family, reflected as different attitudes and behaviors between parents of sons and daughters (Raley and Bianchi 2006). For fathers and mothers, the impact of children's gender is presented in different directions. Effect of children's gender on their father seems to indicate a number of possibilities. The father might witness gender discrimination against women and become more egalitarian in his upbringing of a daughter (Warner and Steel 1999), but he might also, due to father-son preference, become more involved in child rearing and domestic housework and become even more in line with the role of a homemaker (Mammen 2011). Comparing with the contradictory impact of children's gender on the father, the effect for the mother has shown a high level of consistency. Son's presence would lead the mother to a more traditional tendency in attitudes and behaviors, such as being more conservative (Oswald and Powdthavee 2010, getting married faster because of the son, saving more money for the future of her son, or maintaining the marriage (even with extensive marital tensions) to secure a healthy environment for the son (Dahl and Moretti 2008). This difference shows that the effect of children's gender on parental gender attitudes and behaviors may be moderated by motherhood.

Downey and other colleagues criticized the ignorance in previous social science research in the impact of children's characteristics on gender ideology of parents. They found that the higher the number of sons, the more likely the mothers tend to support the idea that "working mothers are not conducive to the growth of children" (Downey et al. 1994). Warner's research conducted in Detroit and Toronto found that mothers from the USA and Canada with only daughters and Canadian fathers are more biased in favor of egalitarian gender ideology; gender of children, however, had no significant 
impact on American fathers (Warner 1991). Downey and Warner's studies showed that having sons or daughters may impose different effects on gender attitudes of parents (especially mothers). The former makes mothers to prefer a more gender traditionalistic view while the latter makes mothers to prefer egalitarian views. Downey and Warner's studies both present certain problems: in the former, the sample is limited to mothers with school-age children, the sample size is small, and it lacks samples of other types of mother and father and the latter is only a rough comparison of "having sons or daughter or not" without a full theoretical analysis on the results. Their exploratory studies failed to effectively explain the mechanism for the impact of children's gender and did not lead subsequent studies to focus on the gender of children. Therefore, we consider it necessary to combine specific social environment and cultural values again to discuss the mechanisms and effects of the impact of children's gender on gender ideology of parents. Based on China's history, we believe the impact of the son on the mother is worth deeper interpretation and focus once again.

\section{Effects of sons on the gender ideology of Chinese mothers}

We believe that, under the triple force of traditional son preference, the structure of the patriarchal system and the dependent status of women, children's gender, especially if the child is a son, will affect the gender ideology of Chinese mothers in family practice.

While whether there is a gender preference in Western society is a controversial phenomenon, the tradition and reality of son preference in East Asia, South Asia, and such regions is one of the social consensuses of the scientific community (Raley and Bianchi 2006). Son preference stems from the Confucius culture and social functions of sons in people's daily practice. The social functions are mainly seeing sons as economic sources, as pensions, and with religious function. First, a long agricultural tradition and agricultural production require high physical demands, and men became the economic sources for the family. A son will bring the family a daughter-in-law through marriage, and the daughter-in-law can also participate in farming or sideline production that create benefits for the family. Daughters, on the other hand, not only because of her marriage that she would become a loss of economic resources for the family but also that she would further debilitate financial conditions with the marriage dowry. That is why the son has a more important economic function (Yang 2012). Secondly, Confucian culture emphasizes the importance of filial piety. The son is a permanent member of the family and charged with the duty to support their parents. The daughter is considered to be a temporary member of the family, and after getting married, the daughter is considered an integral part of her husband's family. Thus, the son as a secured pension is a function predetermined by values and culture (Wang and Pan 2005). Finally, in the cultural tradition of ancestor worship, only sons can serve as inheritance for the blood and transfer the family surname. Only male offsprings can offer incense during the worship of ancestors. Without a son, people believe that they would turn into "evil spirits" after death. So for families, the son has a more important symbolic meaning in religion than the daughter (Gupta et al. 2003).

Traditional son preference in family practice is reflected in the impact of children's gender on family investments, which is associated with social class (Trivers and Willard 1973). In China, it is reflected in the men's social class position in a patriarchal 
structure. Under the background of traditional Chinese patriarchal society, only males have the opportunity to expand the scale of the family and enhance the family status. This situation continues to remain the truth till the end of the 19th century. Xiaotong Fei pointed out that only the male is the core of China's family network, "For Chinese families, the route of expansion is patrilineal; it incorporates only those from the father's side of the family. With few exceptions, families do not include daughters-in-law and sons-in-law at the same time." (Fei 2008, p. 30). Investment in male offspring is almost the only option to expand the family network. Thus, sons receive more attention than daughters of the same generation from the family. Although the contemporary patriarchal Chinese society has constantly been challenged, Chinese families still tend to invest in male offspring. Empirical studies have found that households with sons will increase investments in agricultural production and economic, which are economic activities investments for the development of the son (Ding and Zhang 2014).

Son preference and traditional patriarchal family structures make Chinese families pay more attention to the son. This gender difference may influence the social status of female and then crystallize in the identity and cognitive role of the mother in the realm of division of labor and behavioral patterns. In the traditional Confucian culture and patriarchal environment, the male is the heir and "pillar" to the family and the social status of women is attached to her father, husband, and son-the so-called "A woman is to obey her father before marriage, her husband during married life, and her son in widowhood." This dependent status of women in Chinese society started from a traditional agricultural society and continued to the modern society. It failed to experience major changes from the establishment of the new China to the 1980s (Walder 1989). This inequality has changed since the reform and opening up, but it did not fundamentally change the traditional gender division of labor and gender ideology (Gu 2013). Previous studies have found that the social status of women is an important factor in shaping gender preference. Countries with low social status of women have a higher degree of preference for sons (Arnold and Liu 1986). Xiaotong Fei in his anthropological survey on daughter-in-law found that: "Similarly her position will be strengthened if she bears a child especially a boy" (Fei, 2007, p. 47); otherwise, the woman will be considered incompetent and then subjected to discriminatory treatment from the parents-in-law and other relatives of her husband. In an environment with son preference and traditional patriarchal family structures, the son gives the Chinese mother a higher social status and a greater right to speak in the family. Therefore, compared with mothers without a son, those with sons benefit more from a society with son preference and develop a higher degree of recognition of this cultural value. Accordingly, their thoughts and behavioral patterns are more align with the traditional model provided by this culture. We therefore believe that the son will enhance the traditional tendency of gender ideology for Chinese mothers.

The above discussion implies a potential hypothesis that the impact of children's gender on the gender ideology of parents in Chinese society may be subject to the moderation of motherhood. We propose the following hypothesis:

Hypothesis 2: In Chinese society, having at least one son will increase the mother's support for a more traditional gender ideology.

If hypothesis 2 is supported, we will further explore whether there is a potential correlational logic in Chinese society and whether the son has a stronger impact on the 
traditional gender ideology of parents (especially mothers) than the daughter. However, relevant empirical research only examined the differences of having sons or daughters, and without empirical data on the direct contrast of sons and daughters, the authors can hardly combine empirical results with theoretical derivation to propose such hypothesis. This paper attempts to utilize the division of gender structure, using respondents with only daughters as the reference group, and explore whether there is a difference in the impact of sons and daughters on the gender ideology of parents.

\section{Methods}

\section{Data and sample}

We use Chinese General Social Survey (CGSS) 2013 Data to analyze the impact of children's gender on the gender ideology of parents. The CGSS data is a national sample. Thus, results based on CGSS analysis can be inferred at the national level. The CGSS2013 data was collected through stratified multi-stage probability sampling design and sampled a total of 480 villages/neighborhoods, from which 25 families were extracted at each unit. It used KISH Table Selection to gather respondents and obtained data in the form of structured interviews. The response rate was $72.17 \%$, resulting in a total of 11,438 valid questionnaires. Because this study was designed to explore the influence of children's gender on parental gender ideology and to avoid selective bias due to respondents' subjective fertility differences, we limited our sample to married couples with children, and a total sample size of 8339 was entered into the analytical model.

\section{Dependent variables}

The "social attitude" part of the CGSS questionnaire include five issues that are relevant to gender ideology: (1) "Men are work-orientated, women are family-oriented;" (2) "Men are born more capable than women;" (3) "Doing the job well is no better than marrying well;" (4) "During the economic downturns, female employees should be laid off first;" and (5) "The husband and wife should be equally sharing housework." The respondents were asked to give answers to the above statements using a five-point Likert scale indicating their level of agreement. Among the statements, "men are workorientated, women are family-oriented" and "the husband and wife should be equally sharing housework" reflect the gender division of household in gender ideology; "men are born more capable than women" and "during the economic downturns, female employees should be laid off first" reflect the competitiveness of male and female in gender ideology; and "doing the job well is no better than marrying well" reflects both the dependent status of women in Chinese culture as well as the autonomy in gender ideology.

This study assigned values based on the 5-point Likert scale of the degree of agreement: 1 = Strongly disagree, $2=$ Disagree, $3=$ Neither agree nor disagree, $4=$ Agree, 5 = Strongly agree ("the husband and wife should be equally sharing housework" was reverse coded). The higher the value, the higher the respondents possessed a traditionalism tendency in gender ideology. In this study, an average value of the abovementioned five statements was calculated to represent gender ideology. The reliability coefficient for overall gender ideology was 0.603 , an acceptable level in psychometrics. To test whether the synthetic methods herein may affect the results, the authors also re-examined the same question using factor analysis as a robustness test. 


\section{Independent variables}

In the operationalization of the number of children, there are usually options-"having children or not" and "whether children were home". Between them, "whether the child, son or daughter is at home" is usually associated with the phenomenon of domestic gender division of labor, but "where there is a child, son or daughter," as a major event in life, has a closer relationship with gender ideology. In this study, we adopted a sample with married couple who have children, so using "how many of children" (number of children) than "how many children are staying at home" is more suitable for the analysis of the impact of children on parental gender ideology. In the "family" section of the CGSS survey, we chose to use "the number of children" to measure the gender of the children. The question was "How many children do you have (including stepchildren; if none, please write 0)?" After measuring "number of sons" and "number of daughters," we defined "having sons," namely having at least one son, as a dichotomous variable, where having more than or equal to one son was labeled 1, and having no son was labeled as 0 (having at least one son $=1,75.82 \%$ of the total sample; having no son $=0,24.18 \%$ of the total sample). "Having a daughter" was measured the same way (having at least one daughter $=1,63.41 \%$ of the total sample; having no daughter $=0,36.59 \%$ of the total sample). By calculating the number of sons and daughters, we constructed a continuous variable, "number of children" (Mean =1.934, $\mathrm{SD}=1.156)$. We categorized the gender structure of children into having only sons (36.59\%), only daughters (24.18\%), and both sons and daughters (39.24\%) and constructed an appropriate dummy variable accordingly. Having only daughters was used as the reference group.

\section{Control variables}

According to the existing research, this study controlled for a series of variables that may affect gender ideology, such as demographic variables. Among them, gender (female $=1,50.21 \%$ of the total sample; male $=0,49.79 \%$ of the total sample) and ethnicity ( $\operatorname{Han}=1,91.86 \%$ of the total sample; minority $=0,8.14 \%$ of the total sample) were defined as dichotomous variables. Age and age-squared were defined as continuous variables. In order to reflect the impact of the Hukou (household register) system, we defined the type of Hukou as urban and rural Hukou (urban Hukou $=1,43.54 \%$ of the total sample; rural household $=0,56.46 \%$ of the total sample). Communist party membership was measured as a dichotomous variable (Communist member $=1,11.12 \%$ of the total sample; other $=0,88.88 \%$ of the total sample). Control variables associated with religion are religious beliefs and frequency of participation in religious activities, where the former was assigned as having a religion $(=1,11.12 \%$ of the total sample) and no religion $(=0,88.88 \%$ of the total sample); the latter was measured as a continuous variable ranging from 1 to 9, 1 was never participated in religious activities and 9 was participating in religious activities several times a week (Mean $=1.503, \mathrm{SD}=1.477$ ). The level of education was operationalized as a serial of dummy variables with completed elementary school (38.47\%), junior high school (32.20\%), high school (18.30\%), and universities and above (12.03\%), and the completion of elementary school was the reference group. Frequency of Internet usage was defined as a continuous variable from 1 to 5 (corresponding to the frequency range from "never" to "very often", Mean $=1.942, \mathrm{SD}=1.416)$. Working status was measure as currently working $(1,63.90 \%$ 
of the total sample) and currently not working (0,36.10\% of the total sample). Because of the skewness of income distribution, we took the natural logarithm of annual income to use in the model (Mean $=8.568, \mathrm{SD}=3.138)$. In addition, we also controlled for the level of education of the respondent's father and mother ${ }^{1}$.

\section{Analysis and model}

First, we ran descriptive statistical analysis using the CGSS2013 data on the dependent variables, including statistical distribution of gender ideology, and then through OLS regression methods to examine the effects of the gender of child on parental gender ideology. The first step of the regression model included age, gender, and other control variables and was used as a baseline model. The second step of the model added the number of children, having sons (having daughters), and gender structure of children into the baseline model. In the third step, the model included the number of children, having sons or having daughters, and the interaction term of gender structure of children and female (using male as the reference group).

\section{Findings}

\section{Descriptive analysis}

Results showed that the attitudes of gender ideology for married Chinese parents mainly fall between "disagree" and "agree." The composite score averaged from the five questions on gender ideology has a mean value of 2.81 and a standard deviation of 0.67 . The vast majority of married Chinese parents tend to cluster around the vicinity of 3 , and only a minor proportion responded in the vicinity of 1 and 5 . The 25, 50, and 75 quantiles were 2.4, 2.8, and 3.4, respectively. The 50 quantile (or median) was 2.8, in between "disagree" and "neither agree nor disagree." This means that half of married Chinese parents identifies with traditional gender ideology less than 2.8. The mean and median of the overall gender ideology score are slightly less than 3 , indicating that married Chinese parents slightly disagree with the traditional gender ideology.

\section{The effects of control variables}

The effects of gender, Hukou, Communist party membership, level of education, frequency of Internet usage, and working status, as well as personal income and other control variables of parents on gender ideology are shown in model 1 in Table 1. Among them, women preferred egalitarian gender ideology more than men did $(B=-0.119, p<0.001)$. Age and its squared value had a positive significant effect on the dependent variable, indicating that people in the age distribution of gender ideology exhibit non-linear and non-monotonic characteristics. Respondents with urban Hukou $(B=-0.119, p<0.001)$ and the Communist party membership $(B=-0.104, p<0.001)$ preferred egalitarian gender ideology. Religion had no significant effect on the dependent variable, but the frequency of participation in religious activities enhanced the traditional tendency of gender ideology $(B=0.014, p<0.05)$. However, such influence lost statistical significance when adding key variables in subsequent models. With respect to elementary school education, junior high, high school, and college and above all had a significant negative correlation with the dependent variable. Frequency of Internet usage was negatively correlated with the dependent variable $(B=-0.019, p<0.01)$. Income level enhanced egalitarian gender ideology of respondents 
Table 1 Summary of OLS regression models of the impact of children on parental gender ideology $(N=8339)$

\begin{tabular}{|c|c|c|c|c|c|c|}
\hline \multirow[t]{2}{*}{ Variables } & \multicolumn{2}{|l|}{ Model 1} & \multicolumn{2}{|l|}{ Model 2} & \multicolumn{2}{|l|}{ Model 3} \\
\hline & B & SE & B & SE & B & SE \\
\hline Gender (male =0) & $-0.119^{* * *}$ & 0.015 & $-0.121^{* * *}$ & 0.015 & $-0.212^{* * *}$ & 0.028 \\
\hline Age & $0.002^{* * *}$ & 0.001 & 0.001 & 0.001 & 0.001 & 0.001 \\
\hline Age-squared & $0.000^{* * *}$ & 0.000 & $0.000^{* * *}$ & 0.000 & $0.000^{* * *}$ & 0.000 \\
\hline Ethnicity & 0.022 & 0.027 & 0.027 & 0.027 & 0.024 & 0.027 \\
\hline Type of Hukou & $-0.119^{* * *}$ & 0.018 & $-0.107^{* * *}$ & 0.019 & $-0.109^{* * *}$ & 0.019 \\
\hline Communist party membership & $-0.104^{* * *}$ & 0.024 & $-0.104^{* * *}$ & 0.024 & $-0.103^{* * *}$ & 0.024 \\
\hline Religious belief & -0.044 & 0.031 & -0.042 & 0.031 & -0.043 & 0.031 \\
\hline Frequency of participation in religious activities & $0.014^{*}$ & 0.007 & 0.013 & 0.007 & 0.012 & 0.007 \\
\hline \multicolumn{7}{|l|}{ Level of education (elementary school or below $=0$ ) } \\
\hline Secondary school & $-0.170^{* * *}$ & 0.019 & $-0.164^{* * *}$ & 0.019 & $-0.157^{* * *}$ & 0.019 \\
\hline High school & $-0.221^{* * *}$ & 0.024 & $-0.214^{* * *}$ & 0.024 & $-0.207^{* * *}$ & 0.024 \\
\hline College and above & $-0.242^{* * *}$ & 0.033 & $-0.235^{* * *}$ & 0.033 & $-0.230^{* * *}$ & 0.033 \\
\hline Frequency of internet usage & $-0.019^{* *}$ & 0.007 & $-0.018^{* *}$ & 0.007 & $-0.019^{* *}$ & 0.007 \\
\hline Working status & 0.018 & 0.019 & 0.014 & 0.019 & 0.013 & 0.019 \\
\hline Income & $-0.012^{* * *}$ & 0.003 & $-0.011^{* * *}$ & 0.003 & $-0.011^{* * *}$ & 0.003 \\
\hline Education level of father & -0.002 & 0.004 & -0.002 & 0.004 & -0.002 & 0.004 \\
\hline Education level of mother & -0.003 & 0.006 & -0.003 & 0.006 & -0.003 & 0.006 \\
\hline Number of children & & & $0.026^{* * *}$ & 0.008 & 0.001 & 0.010 \\
\hline Female $\times$ number of children & & & & & $0.048^{* * *}$ & 0.012 \\
\hline Constant & $3.209^{* * *}$ & 0.047 & $3.149^{* * *}$ & 0.051 & $3.197^{* * *}$ & 0.052 \\
\hline Adjusted $R^{2}$ & 0.082 & & 0.083 & & 0.084 & \\
\hline$F$ & 47.42 & & 45.30 & & 43.70 & \\
\hline
\end{tabular}

${ }^{*} p<0.05,{ }^{* *} p<0.01,{ }^{* * *} p<0.001$

( $B=-0.012, p<0.001)$. Ethnicity, working status, and parents' education level did not show statistical significance.

\section{The effects of children}

Table 1 presents the influence of the number of children on gender ideology. Among them, model 1 only included the effects of control variables. Because the same set of control variables was included in different models, we will not repeat the same model in the subsequent analysis. Model 2 shows that the number of children and the dependent variable had a significant positive correlation $(B=0.026, p<0.001)$, supporting that the number of children will increase parents' traditional tendency of gender ideology. But in model 3, when the interaction term of "female" and "number of children" was added, the results showed that the "number of children" was not significant. Particularly important, the interaction term of female and the number of children exhibited a very significant positive effect on parental gender ideology $(B=0.048, p<0.001)$, which indicates the impact of the number of children on gender ideology of parents was moderated by motherhood. Since the main effect was not significant and the interaction effect was significant, we further run a joint $\mathrm{F}$ test of the number of children and its interaction item. Result indicated that the joint effect of the main effect and interaction effect together was still 
significant $(F=13.25, p<0.001)$. Comparing with the effect of the number of children on enhancing the father's traditionalistic gender ideology $(B=0.001)$, its effect on the mother was much greater $(B=0.001+0.048=0.049)$. Therefore, the results supported hypothesis 1 , that is, comparing with the father, the increase in the number of children had a more significant enhancement to the traditionalistic gender ideology of the mother.

\section{The impact of sons and daughters}

We proposed previously that the mother of sons is more likely to have traditionalistic gender ideology (hypothesis 2). This hypothesis was supported in model 4 and model 5 in Table 2. In models 4 and 5, in order to exclude the effect of the number of children on parents, we controlled for the number of children. In models 4 and 5 , the number of children had a significant positive effect on the traditionalistic tendency of parental gender ideology, which is consistent with the results shown in Table 1. As shown in model 4, when controlling for the number of children, having sons did not show statistical significance in affecting the gender ideology of parents. In model 5, the interaction term of female and having sons was added. As in model 4, having sons was still not significant, but the interaction term was significant at the 0.01 level and had a positive

Table 2 Summary of OLS regression models of the impact of having sons on parental gender ideology $(N=8339)$

\begin{tabular}{|c|c|c|c|c|}
\hline \multirow[t]{2}{*}{ Variables } & \multicolumn{2}{|l|}{ Model 4} & \multicolumn{2}{|l|}{ Model 5} \\
\hline & $B$ & SE & $B$ & SE \\
\hline Gender (male $=0$ ) & $-0.121^{* * *}$ & 0.015 & $-0.188^{* * *}$ & 0.029 \\
\hline Age & 0.001 & 0.001 & 0.001 & 0.001 \\
\hline Age-squared & $0.000^{* * *}$ & 0.000 & $0.000^{* * *}$ & 0.000 \\
\hline Ethnicity & 0.027 & 0.027 & 0.026 & 0.027 \\
\hline Type of Hukou & $-0.106^{* * *}$ & 0.019 & $-0.107^{* * *}$ & 0.019 \\
\hline Communist party membership & $-0.104^{* * *}$ & 0.024 & $-0.106^{* * *}$ & 0.024 \\
\hline Religious belief & -0.042 & 0.031 & -0.042 & 0.031 \\
\hline Frequency of participation in religious activities & 0.013 & 0.007 & 0.013 & 0.007 \\
\hline \multicolumn{5}{|l|}{ Level of education (Elementary school or below $=0$ ) } \\
\hline Secondary school & $-0.163^{* * *}$ & 0.019 & $-0.161^{* * *}$ & 0.019 \\
\hline High school & $-0.214^{* * *}$ & 0.024 & $-0.212^{* * *}$ & 0.024 \\
\hline College and above & $-0.234^{* * *}$ & 0.033 & $-0.232^{* * *}$ & 0.033 \\
\hline Frequency of internet usage & $-0.017^{* *}$ & 0.007 & $-0.018^{* *}$ & 0.007 \\
\hline Working status & 0.014 & 0.019 & 0.013 & 0.019 \\
\hline Income & $-0.011^{* * *}$ & 0.003 & $-0.011^{* * *}$ & 0.003 \\
\hline Education level of father & -0.002 & 0.004 & -0.002 & 0.004 \\
\hline Education level of mother & -0.003 & 0.006 & -0.003 & 0.006 \\
\hline Number of children & $0.025^{* *}$ & 0.008 & $0.025^{* *}$ & 0.008 \\
\hline Having sons & 0.012 & 0.017 & -0.031 & 0.024 \\
\hline Female $\times$ having sons & & & $0.089^{* *}$ & 0.033 \\
\hline Constant & $3.140^{* * *}$ & 0.052 & $3.175^{* * *}$ & 0.053 \\
\hline Adjusted R2 & 0.083 & & 0.084 & \\
\hline$F$ & 42.81 & & 40.97 & \\
\hline
\end{tabular}

${ }^{*} p<0.05,{ }^{* *} p<0.01,{ }^{* * *} p<0.001$ 
association with the dependent variable $(B=0.089)$. Further $F$ test indicated that the joint effect of having son and its interaction item was still significant $(F=4.79$, $p=0.008<0.01$, which indicates that the influence of having sons on parental gender ideology was moderated by motherhood. Specifically, due to the positive and statistically significant coefficient of the interaction term, it means that comparing with the father, the son's effect on traditionalistic tendency of gender ideology was stronger for the mother.

In order to reflect more directly whether having a son influences gender ideology, we calculated the group gender ideology for fathers without a son, fathers with sons, mothers without a son, and mothers with sons. The results are shown in Fig. 1. Figure 1 shows that, from the mean value, comparing with mothers without a son, mothers with sons had a stronger traditionalistic gender; relative to fathers without a son, fathers with sons had a stronger traditionalistic gender ideology. But the slope for whether having a son or not on gender ideology was steeper for mothers than for fathers. Thus, hypothesis 2 is supported.

For comparison, we conducted a similar analysis on the effect of having a daughter and gender ideology. The results show that the interaction of having daughters $(B=-0.005$, $p=0.820)$ and motherhood $(B=0.025, p=0.400)$ was not significant. We also calculated the group gender ideology for fathers without a daughter, fathers with daughters, mothers without a daughter, and mothers with daughters. The slope was different for mothers and fathers, but the difference was not as drastic as Fig. $1^{2}$.

\section{The effect of children's gender structure}

Table 3 reflects the impact of the gender structure of children on their parents' gender ideology. We added gender structure of children and the interaction term of motherhood and the gender structure of children, respectively, in the model 6 and model 7 . As shown in model 6, after controlling for the number of children, compared with parents who had only daughters, parents who had only sons or had both sons and daughters did not show significant difference in gender ideology. The results of model 7 show that compared with mothers having only daughters, mothers having only sons were not significantly different in their gender ideology. But mothers who had both sons and daughters were more traditional $(B=0.124, p<0.001)$. Further $F$ test confirmed that the joint effect of having both sons and daughters and its interaction item

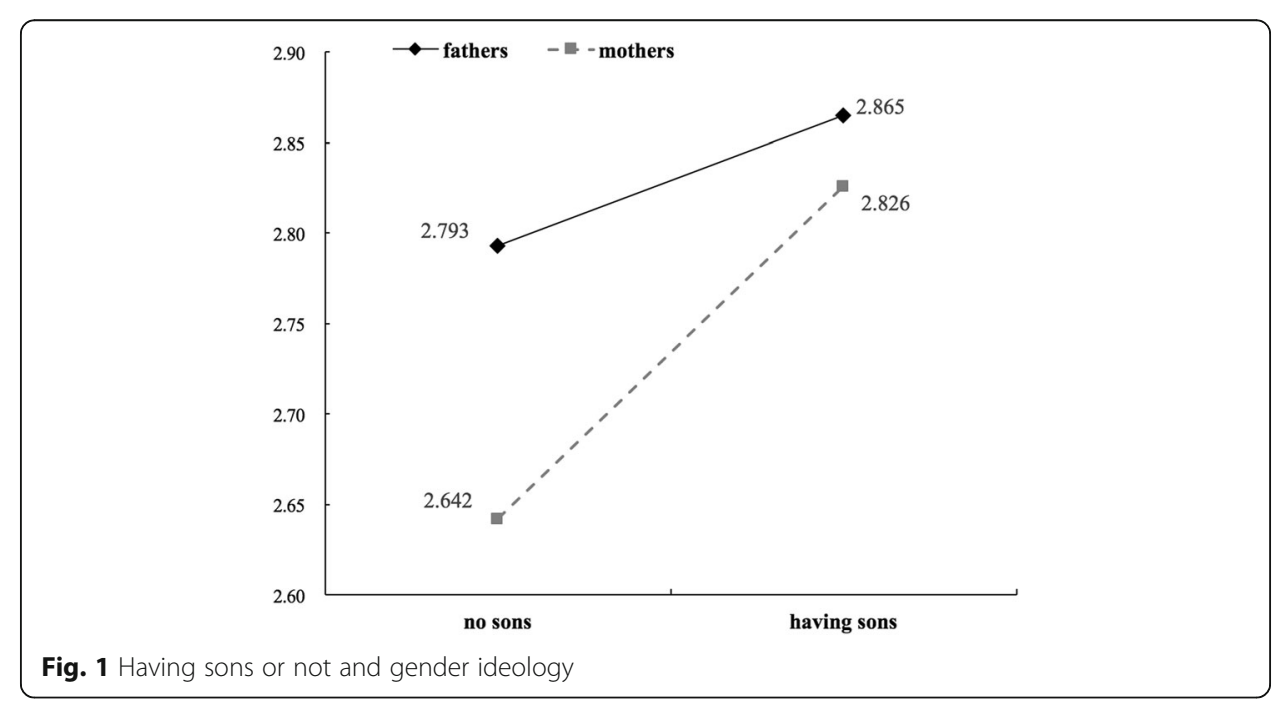


Table 3 Summary of OLS regression models of the impact of children's gender structure on parental gender ideology $(N=8339)$

\begin{tabular}{|c|c|c|c|c|}
\hline \multirow[t]{2}{*}{ Variables } & \multicolumn{2}{|l|}{ Model 4} & \multicolumn{2}{|l|}{ Model 5} \\
\hline & $B$ & SE & $B$ & SE \\
\hline Gender (reference group: male) & $-0.121^{* * *}$ & 0.015 & $-0.188^{* * *}$ & 0.029 \\
\hline Age & 0.001 & 0.001 & 0.001 & 0.001 \\
\hline Age-squared & $0.000^{* * *}$ & 0.000 & $0.000^{* * *}$ & 0.000 \\
\hline Ethnicity & 0.027 & 0.027 & 0.025 & 0.027 \\
\hline Type of Hukou & $-0.106^{* * *}$ & 0.019 & $-0.106^{* * *}$ & 0.019 \\
\hline Communist party membership & $-0.104^{* * *}$ & 0.024 & $-0.105^{* * *}$ & 0.024 \\
\hline Religious belief & -0.042 & 0.031 & -0.042 & 0.031 \\
\hline Frequency of participation in religious activities & 0.013 & 0.007 & 0.013 & 0.007 \\
\hline \multicolumn{5}{|l|}{ Level of education (elementary school or below $=0$ ) } \\
\hline Secondary school & $-0.163^{* * *}$ & 0.019 & $-0.157^{* * *}$ & 0.019 \\
\hline High school & $-0.213^{* * *}$ & 0.024 & $-0.207^{* * *}$ & 0.024 \\
\hline College and above & $-0.233^{* * *}$ & 0.033 & $-0.229^{* * *}$ & 0.033 \\
\hline Frequency of internet usage & $-0.017^{* *}$ & 0.007 & $-0.018^{* *}$ & 0.007 \\
\hline Working status & 0.015 & 0.019 & 0.014 & 0.019 \\
\hline Income & $-0.012^{* * *}$ & 0.003 & $-0.012^{* * *}$ & 0.003 \\
\hline Education level of father & -0.002 & 0.004 & -0.002 & 0.004 \\
\hline Education level of mother & -0.002 & 0.006 & -0.003 & 0.006 \\
\hline Number of children & $0.019^{*}$ & 0.010 & 0.019 & 0.010 \\
\hline Only sons & 0.005 & 0.019 & -0.020 & 0.026 \\
\hline Both sons and daughters & 0.029 & 0.023 & -0.032 & 0.029 \\
\hline Female $\times$ only sons & & & 0.052 & 0.037 \\
\hline Female $\times$ both sons and daughters & & & $0.124^{* * *}$ & 0.037 \\
\hline Constant & $3.146^{* * *}$ & 0.052 & $3.180^{* * *}$ & 0.054 \\
\hline Adjusted $R^{2}$ & 0.083 & & 0.084 & \\
\hline F & 40.63 & & 37.39 & \\
\hline
\end{tabular}

${ }^{*} p<0.05,{ }^{* *} p<0.01,{ }^{* * *} p<0.001$

was still significant $(F=7.86, p<0.001)$. This result suggests that our proposed logic was not supported by empirical data. However, in our robustness check ${ }^{3}$, we found different evidence. With the same variables and model construction mentioned above, we distinguished the gender structure of children (having only son, only daughter, both sons and daughters, and having only daughter was the reference group) and its interaction term with motherhood on the dependent variable. When we further limited the sample in parents with two children, the interaction term of motherhood and having only sons showed a significant positive correlation with the dependent variable at the 0.05 level ( $B=0.157)$. What is more, by using the CGSS2012 data $(N=9175)$, we also found the same result in the full sample that the interaction term of motherhood and having only sons showed a significant positive correlation with the dependent variable $(B=0.070, p$ $<0.05)$. Therefore, findings from the two robustness tests all supported our logical association. Based on these results, we argue that, as a reflection of actionable logic under patriarchal structures and progress of contemporary gender equality, the direct comparison about the impact of sons and daughters on their parents' gender ideology needs more in-depth efforts in future research. 


\section{Robustness test}

To test the robustness of these findings, we used the same measurement of variables and model configuration to recalculate the impact of these variables and the interaction terms on the dependent variables.

First, we used the CGSS2012 data for robustness check. Results of regression models showed that the interaction term of motherhood and the number of children as well as the interaction tem of motherhood and having sons had significant positive correlation with the dependent variables. An increase in the number of children $(B=0.025, p<0.05)$ and having a son $(B=0.078, p<0.01)$ both increased the tendency of traditionalistic gender ideology in mothers. Motherhood played an important moderator role. This indicates high consistency with the findings from CGSS2013.

Secondly, considering the differences in the social structure and cultural values between the urban and rural areas, we restricted samples into respondents with urban or rural Hukou. Regression results of the urban sample showed that the interaction term of motherhood and the number of children had significant positive correlation with the dependent variable while the results for the interaction term of motherhood and having sons did not show significance. Results of regression model of rural sample showed that the interaction term of motherhood and the number of children did not show significance while the results for the interaction term of motherhood and having sons had significant positive correlation with the dependent variable. This is slightly different from the previous results of our study, but it also reflects a classic logic that the children's gender differences were narrowing in urban communities and still existed in rural communities.

Finally, we used factor analysis and principal component analysis to construct a composite index of gender ideology, in place of the original mean composite index to model and test our hypothesis. The results were highly consistent with the previous models. In addition, a conversion of the core independent variable from continuous to dichotomous variable showed that the higher the number of sons, the more a mother biased towards traditionalistic gender ideology. No significant effect of the number of daughters was found, which was also consistent with prior findings. Based on the above results, we argue that the findings in this paper have strong robustness.

\section{Discussion}

Children are considered to be influential in the social values and social attitudes of their parents, such as the concept of fertility, happiness, and political attitudes (Oswald and Powdthavee 2010; Raley and Bianchi 2006). Our study furthered the analysis of scholars like Warner and Downey el al. (Downey et al. 1994; Warner 1991), by finding that the impact of children on parental gender ideology has two possible aspects. First, we expected that the number of children can affect parents' gender ideology. Increasing in the number of children comes with an increase in the gender ideology of parents (especially mothers) to be more traditional. Our study found that the number of children had a significant impact on the Chinese parents' gender ideology. This is inconsistent with findings that "having children or not does not have a significant influence on gender ideology of Chinese people" from scholars using data from "World Values Survey" (WVS) (Shu and Zhu 2012). We suggest that the birth of a child is a major event in the life course of parents, accompanied by both the biological and social 
construction of identity as parents (especially the identity of mother). This influence from this transition for the mind and behaviors of parents has been confirmed. Therefore, this study suggests that it is more likely the case that "having children has a significant impact on Chinese gender ideology" ${ }^{\prime 4}$. When we observe further the interaction of motherhood and having children or not, the interaction term was found to have more explanatory power. The higher the number of children, the more significant bias of traditionalistic gender ideology parents (especially mothers) was found. This result supported hypothesis 1 and confirmed the evidence from Greenstein's research on the gender division of labor on the behavioral level (Greenstein 1996) as well as evidence found in biological evolution and evolutionary psychology research (Alexander 1974).

Secondly, we hypothesized that the impact of children's gender on parental gender ideology would be moderated by motherhood and that mothers with sons would be more traditionalistic in gender ideology. By examining the interaction term, we verified this hypothesis. We found no significant effect on parental gender ideology when the children were daughters. Based on the significant differences found with respect to having sons or not and the lack of significance with daughters on parental gender ideology, we attempted to explore the relative influence of sons and daughters on gender ideology of parents. However, results based on gender structure revealed complexity and uncertainty, which also raised new questions that in contemporary Chinese society, is the influence of a child's gender on the gender ideology of parents still strong with the traditional characteristics (the son of parents are more traditional) or with a more egalitarian characteristic (no difference between children of the two genders)? These issues need more evidence and further research.

At the theoretical level, by involving the three perspectives of the tradition of son preference in Chinese society, the patriarchal system structure and the dependent status of women, this study comprehensively analyzed the mechanism of the motherhood in the impact of children's gender on parental gender ideology. This approach integrated the constructive property of gender into the theoretical explanation, highlighting the influence of "living in the moment" on social values. Indeed, market-oriented reforms have increased women's chance at better educations and the possibility of obtaining a higher income, and their gender ideology will gradually become more egalitarian. But from a historical perspective, China's social structure has an "ultrastable" characteristic (Jin and Liu 1992). Accordingly, the social value has formed a long-term solidification pattern with the core of Confucian culture. Male dominance and the dependent status of women are all highly institutionalized in the economic, political, family, cultural, and other aspects. This institutionalized value of "men work outside, women inside" will take a long practice before it can be changed. This study presented the strengthening effect of the number of children and having sons on the traditionalistic gender ideology tendencies of mothers. We propose that it is the expression of the stability of Chinese social values on the gender ideology of mothers, and also to some extent, this confirmed the rationality of the Cultural Lag Theory of Ogbum.

Our findings furthered existing research on at least two dimensions. First, different from the research paradigm attending to the "parental influence on children," we systematically examined the influence of children on their parents. Secondly, we comprehensively reviewed theoretical and empirical research in sociology, biology, and economics to propose the theoretical explanations for the mechanism behind the 
impact of children's gender on parental gender ideology. What is more, we tried to test them in empirical data and to reveal the inherent biological and social cultural properties in gender ideology. Of course, our study also has disadvantages in two aspects. First, while we found the effect of children's gender on the gender ideology of Chinese parents, will this effect be affected by other characteristics of the children? Unfortunately, other characteristics (such as health) were not included in the survey of CGSS2013, so we cannot verify whether the effect of children's gender is moderated by the aforementioned characteristics. Secondly, the relationship between gender ideology and gender division of labor within family could not be reflected in this study. Studies have shown that gender ideology and the practice of housework affect one another (Carlsona and Lynch 2013). However, this survey did not cover specific housework time. Future research may consider the role of housework on gender ideology.

This study also has strong potential for further implication. This paper reveals that children's gender can affect parents, but this effect may not only result in the dimension of gender ideology. It may also have wider impact on parents' subjective cognition, social attitudes, and such. In addition, we can also focus on the role of changes in social structures and institutional environment in the impact of children's gender. With modernization and the increasing cross-regional migration and occupational mobility, daughters establish increasingly close ties with parents (Cong and Silverstein 2012). In addition, changes in policy to permit having a second child may also lead to changes in the gender structure of children. Whether and to what extent are these changes reflected in the influence of children's gender on the attitudes and behaviors of parents? Finally, the issue of causality in children's gender and parental gender ideology implies that the possibility for parents with higher traditionalistic gender ideology to voluntarily choose a certain gender-specific child. But taking into account the very importance and impact of the birth and upbringing of a child on a family, we argue that the influence of gender on parents cannot be ignored. From the path of western research on children's gender and parenthood issues, almost all studies originated from cross-sectional data comparing "couples (parents) with children" and "childless couples" in their differences in cognition, attitude, and behavioral dimensions (Anderson et al. 2003). With the increasing attention to the problem of endogeneity and heterogeneity and the progress in research methods, time-series data (such as the dataset of NLSYW1968-1988) and fixed effects model analysis have become important ways to study parenthood in recent years (Weinshenker 2015). Unfortunately, to the best of our knowledge, the current domestic longitudinal data projects are still in their early stages. The relevant data to track a 10-year or longer period of time has not yet emerged. However, in recent years, a comprehensive study on parenthood found little difference between the results of cross-sectional data and results based on longitudinal data (Anderson et al. 2003). Of course, in order to better show a causal relationship between children's gender and gender ideology of parents, future studies may be required to use longitudinal data (for example, the changes in gender ideology of parents before and after a child was born) and natural experiments to conduct more rigorous studies.

\section{Endnotes}

${ }^{1}$ Considering the length of the paper, this article does not exhibit descriptive statistics of the variables. Readers may obtain it from the authors. 
${ }^{2}$ Taking into account the length of the paper, the regression model summaries and figures of mean values of whether having a daughter impacts parental gender ideology were not presented in the text. The reader can obtain them from the authors.

${ }^{3}$ Details for the various results on robustness test were not presented in the text, but readers can obtain them from the authors.

${ }^{4}$ To test this hypothesis, we also increased the sample size to the whole sample, to test the effect of "having children or not" on the gender ideology of Chinese people. The results from regression models found that whether having children or not alone had no significant effect on the dependent variable, which is consistent with the WVS data. But when we included the interaction term of motherhood and having children or not into the model, we found a significant effect on the dependent variable, and the effect was moderated by the role of motherhood. The interaction term was positively correlated with the dependent variable at 0.001 level. The results are similar to what were found in this paper, indicating that the children do increase the traditionalistic tendency of gender ideology for Chinese parents (especially mothers).

\section{Acknowledgments}

The authors are grateful for the advice from Chuhui Wang, Hao Chen, and Yan Wang at Nankai University, as well as Dr. Chuan Lin. We also thank anonymous reviewers for their valuable comments. The data used in this paper comes from the "Chinese General Social Survey (CGSS)" project hosted by the National Survey Research Center at Renmin University of China. The authors are solely responsible for the contents of this paper.

\section{Authors' contributions}

SX proposed the idea, cleaned the data, operationalized the analytic models, and drafted the manuscript. LK proposed the analytic framework, tested the models, participated in the design of the paper framework, and revised the drafts. Both authors read and approved the final manuscript.

Competing interests

The authors declare that they have no competing interests.

\section{Author details}

${ }^{1}$ Zhou Enlai School of Government, Nankai University, No. 38, Tongyan Road, Jinnan District, Tianjin, China. ${ }^{2}$ School of Communication and Design, Sun Yat-sen University, No. 132, Waihuan East Road, Panyu District, Guangzhou, China.

Received: 21 August 2016 Accepted: 5 December 2016

Published online: 05 January 2017

\section{Reference}

Alexander, R.D. 1974. The evolution of social behavior. Ann rev ecol syst 5: 325-383.

Alvergne, A., C.H. Faurie, and M. Raymond. 2009. Father-offspring resemblance predicts paternal investment in humans. Anim Behav 78(1): 61-69.

Anderson, D.J., M. Binder, and K. Krause. 2003. The motherhood wage penalty revisited: Experience, heterogeneity, work effort, and work-schedule flexibility. Ind Labor Relat Rev 56(2): 273-294.

Arnold, F., and Z. Liu. 1986. Sex preference, fertility, and family planning in China. Popul Dev Rev 12: 221-246.

Bass, B.C. 2015. Preparing for parenthood? Gender, aspirations, and the reproduction of labor market inequality. Gend SOC 29(3): 362-385.

Becker, G.S. 1991. A Treatise on the Family. Cambridge: Harvard University Press.

Bem, S.L. 1993. The Lenses of Gender: Transforming the Debate on Sexual Inequality. New Haven: Yale University Press.

Bianchi, S.M., and M.A. Milkie. 2010. Work and family research in the first decade of the 21st century. J Marriage Fam 72(3): 705-725.

Brewster, K.L., and I. Padavic. 2000. Change in gender-ideology, 1977-1996: the contributions of intracohort change and population turnover. J Marriage Fam 62(2): 477-487.

Buss, D. 1999. Evolutionary Psychology: the New Science of the Mind. Boston: Allyn \& Bacon.

Carlsona, D.L., and J.L. Lynchb. 2013. Housework: Cause and consequence of gender ideology? Soc Sci Res 42(6): 1505-1518.

Cha, Y., and S. Thebaud. 2009. Labor markets, breadwinning, and beliefs how economic context shapes men's gender ideology. Gend Soc 23(2): 215-243.

Cong, Z., and M. Silverstein. 2012. A vignette study on gendered filial expectations of elders in rural China. J Marriage Fam 74(3): 510-525.

Dahl, G.B., and E. Moretti. 2008. The demand for sons. Rev Econ Stud 75(4): 1085-1120.

Davis, S.N., and T.N. Greenstein. 2009. Gender ideology: Components, predictors, and consequences. Annu Rev Sociol 35: 87-105.

Dawkins, R. 2016. The selfish gene. New York: Oxford University Press. 
Ding, W., and Y. Zhang. 2014. When a son is born: The impact of fertility patterns on family finance in rural China. China Econ Rev 30: 192-208.

Downey, D.B., P.B. Jackson, and B. Powell. 1994. Sons versus daughters. Sociol Q 35(1): 33-50.

Evertsson, M. 2014. Gender ideology and the sharing of housework and child care in Sweden. J Fam Issues 35(7): 927-949.

Fei, Xiaotong. 2007. Jiang Village Economy. Shanghai: Shanghai Century Publishing Group.

Fei, Xiaotong. 2008. Peasant Life in China. Beijing: People's Publishing House.

Goffman, E. 1997. Gender Display. In Gender Advertisements: Studies in the Anthropology of Visual Communication. London: Macmillan Education.

Goldscheider, F., C. Goldscheider, and A.R. Gonzalez. 2014. Gender Equality in Sweden: Are the Religious More Patriarchal? J Fam Issues 35(7): 892-908.

Greenstein, T.N. 1996. Husbands' participation in domestic labor: Interactive effects of wives' and husbands' gender ideologies. J Marriage Fam 58: 585-595.

Gu, Hui. 2013. A Review on State, Market and the Traditional Social Gender. Acad 6: 104-114.

Gupta, S. 2007. Autonomy, dependence, or display? The relationship between married women's earnings and housework. J Marriage Fam 69(2): 399-417.

Gupta, M.D., Z. Jiang, B. Li, Z. Xie, W. Chung, and B. Hwa-Ok. 2003. Why is son preference so persistent in East and South Asia? A cross-country study of China, India and the Republic of Korea. J Dev Stud 40(2): 153-187.

Hamilton, W.D. 1964. The genetical evolution of social behaviour. II. J theor biol 7(1): 17-52.

Hanks, M.W. 2007. World history and the history of women, gender, and sexuality. J World Hist 18(1): 53-67.

Jin, Guantao, and Qingfeng Liu. 1992. The cycle of growth and decline: on the ultra-stable structure of Chinese society. Hong Kong: Chinese University of Hong Kong Press.

Kaufman, G., and P. Uhlenberg. 2000. The influence of parenthood on the work effort of married men and women. Soc Forces 78(3): 931-947.

Kodagoda, T. 2014. Working mothers' gender ideologies on childcare and perception on existing childcare centres: Life stories from Sri Lanka. Gender in Manag Int J 29(7): 402-418.

Mammen, K. 2011. Fathers' time investments in children: do sons get more? J Popul Econ 24(3): 839-871.

Mason, K.O., and Y. Lu. 1988. Attitudes toward women's familial roles: Changes in the United States, 1977-1985. Gen Soc 2(1): 39-57.

Ogbum, W.F. 1922. Social change, with respect to culture and original nature. New York: Huebsch.

Oswald, A.J., and N. Powdthavee. 2010. Daughters and left-wing voting. Rev Econ Stat 92(2): 213-227.

Raley, S., and S. Bianchi. 2006. Sons, daughters, and family processes: Does gender of children matter? Annu Rev sociol 32: $401-421$.

Risman, B.J. 2004. Gender as a social structure theory wrestling with activism. Gen soc 18(4): 429-450.

Roder, A., and P. Muhlau. 2014. Are They Acculturating? Europe's Immigrants and Gender Egalitarianism. Soc Forces 92(3): 899-928.

Shu, X., and Y. Zhu. 2012. Uneven transitions: Period-and cohort-related changes in gender attitudes in China, $1995-2007$. Soc Sci Res 41(5): 1100-1115.

Taylor, P.L., M.B. Tucker, and C. Mitchell-Kernan. 1999. Ethnic variations in perceptions of men's provider role. Psychol Women Q 23(4): 741-761.

Thornton, A., and H.S. Lin. 1994. Social change and the family in Taiwan. Chicago: University of Chicago Press.

Trivers, R.L., and D.E. Willard. 1973. Natural selection of parental ability to vary the sex ratio of offspring. Science 179(4068): 90-92.

Udry, J.R. 2000. Biological limits of gender construction. Am Sociol Rev 65: 443-457.

Walder, A.G. 1989. Social change in post-revolution China. Annu Rev Sociol 15: 405-424.

Wang, Wenqing, and Sui-ming Pan. 2005. Review on a Preference of Son. Sociol Stud 6: 165-193.

Warner, R.L. 1991. Does the sex of your children matter? Support for feminism among women and men in the United States and Canada. J Marriage Fam 53: 1051-1056.

Warner, R.L., and B.S. Steel. 1999. Child Rearing as a Mechanism for Social Change: The Relationship of Child Gender to Parents' Commitment to Gender Equity. Gen Soc 13(4): 503-517.

Weinshenker, M. 2015. The Effect of Fatherhood on Employment Hours Variation by Birth Timing, Marriage, and Coresidence. J Fam Issues 36(1): 3-30.

West, C., and D.H. Zimmerman. 1987. Doing gender. Gen soc 1(2): 125-151.

Whitehead, A.L. 2012. Gender ideology and religion: Does a masculine image of God matter? Rev Relig Res 54(2): 139-156.

Worthman, C.M. 1995. Hormones, sex, and gender. Ann Rev Anthropol 24: 593-617.

Yang, Juhua. 2012. Son Preference and Gender Imbalance: A Theoretical Framework Based on Demand Perspective. Collection of Women's Stud 2: 23-35.

Yu, W.H., and P.L. Lee. 2013. Decomposing gender beliefs: Cross-national differences in attitudes toward maternal employment and gender equality at home. Sociol Inq 83(4): 591-621. 